\title{
An investigation into the relationship between cigarette smoking and diverticular disease of the colon
}

\author{
Christopher G Jamieson, MB, BS, FRCSC, FACS, MiChaEl J WeINBERG, BSC, MSC, JOANNE LORRAINE, MD
}

ABSTRACT: A retrospective study was conducted to determine the relationship between cigarette smoking and diverticular disease of the colon. One hundred and two patients undergoing barium enema were assessed for diverticular disease and smoking history. No significant positive association between smoking and diverticular disease was found. Can J Gastroenterol 1990;4(5):193-195

Key Words: Barium enema, Diverticular disease, Smoking

\section{Tabagisme et diverticulose}

RESUME: Une étude rétrospective a été effectuée afin de déterminer le rapport existant entre l'usage de la cigarette et la diverticulose. Cent-deux patients ont été interrogés sur leur mode de vie et ont subi un lavement baryté visant à révéler la présence de diverticules. Aucune association significative n'a été établie entre le tabagisme et la diverticulose.

D IVERTICULAR DISEASE IS A COMmon condition especially in the older population, occurring in more than $35 \%$ of persons over the age of 65 (1). The prevalence of diverticular disease is much higher in the western world and in certain ethnic groups, and increases with age (2-4).

The causes of diverticular disease are complicated. However, pressure changes in response to eating or neuropharmacologic cholinergic stimuli
Department of Surgery, The Wellesley Hospital, Toronto, Ontario

Correspondence and reprints: Dr C Jamieson, Suite 322 Jones Building, 160 Wellesley Street East, Toronto, Ontario M4Y IJ3. Telephone (416) $926-7749$

Received for publication March 28, 1990. Accepted May 15, 1990 are generally accepted as responsible for the eventual herniation of mucosa through breaks in the muscle at the site of penetration by small arteries, with the formation of typical diverticular $\operatorname{sacs}(4)$.

Tobacco smoking has been implicated as a factor in the pathogenesis of several gastrointestinal diseases $(5,6)$, although no studies have looked at its relationship to diverticular disease.

It was hypothesized that cigarette smoking, through nicotine, could increase the colonic intraluminal pressure and thus contribute to the development of diverticula. Nicotine, a significant constituent of cigarettes, stimulates contractile activity of the distal descending colon (7) and can be sufficiently forceful to cause defecation in unanesthetized animals (8). Smoking has also been shown to increase intestinal motility in humans (9).

An alternative mechanism proposed was through vascular compromise as a result of arteriosclerosis. Diverticular disease and arteriosclerosis are as- 


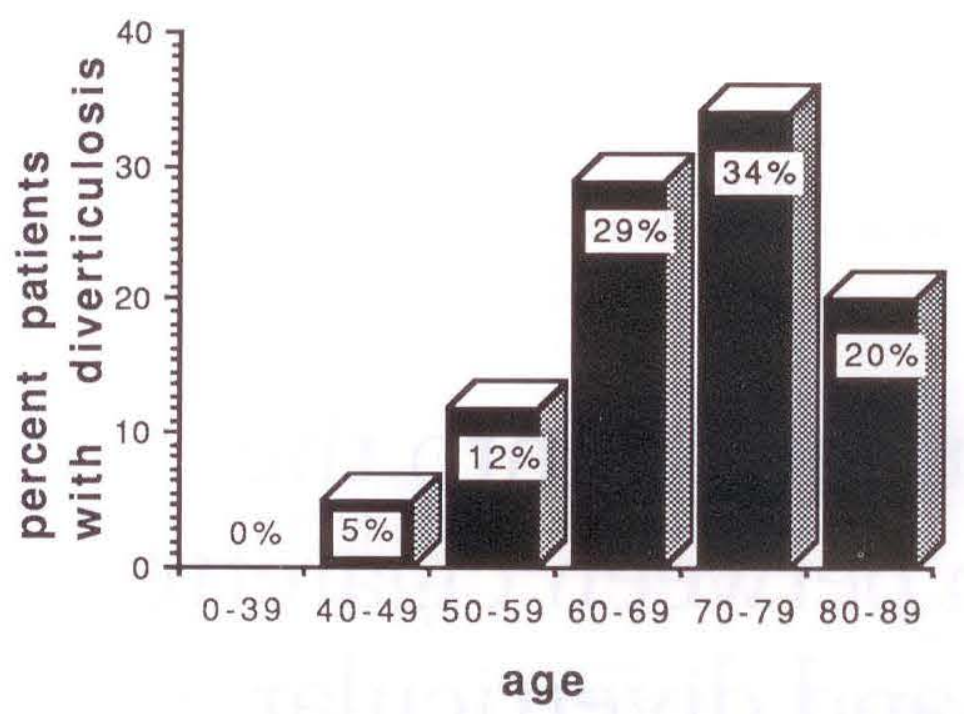

Figure 1) Prevalence of diverticular disease with age in 41 patients

TABLE 1

The number and percentage of smokers and nonsmokers with and without diverticula

\begin{tabular}{lccc}
\hline & Smokers & Nonsmokers & Total \\
\hline Diverticula present & $27(66 \%)$ & $14(34 \%)$ & 41 \\
Diverticula absent & $40(66 \%)$ & $21(34 \%)$ & 61 \\
Total patients & $67(66 \%)$ & $35(34 \%)$ & 102 \\
\hline
\end{tabular}

sociated in that they have the same geographic distribution, and both affect the older age group (10).

\section{PATIENTS AND METHODS}

All patients who were referred to a hospital radiology department for outpatient barium enemas over a four month period were chosen for entry into a retrospective study. Of the 200 patients contacted, 102 patients supplied complete and reliable smoking histories and were thus included.

The smoking data obtained was organized into a 'pack-year' system. 'One pack-year' was defined as one package a day for one year. Nonsmokers were defined as patients who had never smoked cigarettes.

The barium enemas were performed by double contrast technique and were reviewed by one radiologist who was not aware of the smoking histories of the patients. The radiologic criterion for the diagnosis of diverticular disease was the presence of one or more visible diverticula.

\section{RESULTS}

The prevalence of diverticular disease increased with age (Figure 1). No diverticula were found earlier than the fourth decade of life.

The sigmoid colon was the most common anatomic site for diverticula (seen in $85 \%$ of patients with diverticula). Other sites, in order of decreasing frequency, were descending (56\%), transverse $(32 \%)$, and ascending colon (32\%).

Forty-one of the 102 patients had diverticula on barium enema. Sixtyseven had a positive smoking history. The percentage of patients with a smoking history was identical in patients with diverticula to those without diverticula (Table 1).

The incidence of diverticular disease did not change with increasing numbers of cigarettes smoked (Table 2).

\section{DISCUSSION}

The data in the present study are in general agreement with other studies with respect to age distribution and anatomic site of diverticula $(2,4,11)$.

The data failed to provide evidence that diverticular disease is associated with a history of smoking or the num. ber of cigarettes smoked in a lifetime. There are many difficulties that arise when undertaking experimental work into the effects of cigarette smoking, which were well recognized in a study that reviewed cigarette smoking and inflammatory bowel disease (12). For example, there are in excess of 3900 chemicals in cigarette smoke, and it is perhaps naive to propose an effect due to one component (13).

The endpoint chosen for this study was the absence or presence of diverticula. Barium enema is a widely used and sensitive measure of diverticula $(3,14)$. No attempt was made to quantitate the number of diverticula nor the severity of symptoms. Thus it is possible that the study was not sufficiently sensitive, although this is unlikely since the number of patients with diver. ticular disease did not increase with the number of cigarettes smoked.

The most evident source of error in this study is selection bias, as only patients who needed a barium enema were included. However, most data on

\section{TABLE 2 \\ Relationship between cigarette pack-years and the incidence of diverticulosis}

\begin{tabular}{ccc}
\hline Pack-years & $\begin{array}{c}\text { No. of } \\
\text { patients }\end{array}$ & $\begin{array}{c}\text { Percentage with } \\
\text { diverticulosis }\end{array}$ \\
\hline 0 & 35 & 40 \\
$0-9$ & 16 & 25 \\
$10-19$ & 11 & 55 \\
$20-29$ & 6 & 50 \\
$30-39$ & 10 & 33 \\
$40-49$ & 7 & 43 \\
$50-59$ & 5 & 40 \\
$60-69$ & 5 & 80 \\
$70-79$ & 1 & 100 \\
$80-89$ & 2 & 50 \\
$90-99$ & 0 & 0 \\
$>100$ & 4 & 0 \\
\hline
\end{tabular}


diverticular disease have been collected in this way (4). The finding that $67 \%$ of patients in this study had smoked cigarettes in their lifetime is consistent with the current estimated prevalence of $35 \%$ in the general population (15).

The physiologic effects of nicotine

\section{REFERENCES}

1. Memiche R, Williams CN. Diverticular disease of the colon. Med Clin North Am 1988;19:3683-9.

2. Connell AM. Pathogenesis of diverticular disease of the colon. Adv Intern Med 1977;22:377-95.

3. Janower ML. Diverticulitis and the contrast enema. Am J Radiol 1987:149:861-2. (Lett)

4. Mendeloff AI. Thoughts on the epidemiology of diverticular disease. Clin Gastroenterol 1986;15:855-77.

5. Fielding JE. Smoking: Health effects and control. N Engl J Med 1985:313:491-8.

6. Kikendall JW, Evaul J, Johnson LF. Effect of cigarette smoking on gastrointestinal physiology and nonneoplastic digestive disease. J Clin Gastroenterol 1984;6:65-79.

7. Weisbrodt NW, Hug CC Jr, Schmiege SK Bass P. Effects of nicotine and have not been studied extensively in man and thus it is possible that levels during smoking are not high enough to stimulate the colon significantly. There is controversy (6) about the interpretation of the data in unanesthetized animals (8) in which the effect is explained by catecholamine release from

tyramine on contractile activity of the colon. Eur J Pharmacol 1970;12:310-9.

8. Carlso GM, Ruddon RW, Hug CC Jr,

Bass P. Effects of nicotine on gastric antral and duodenal contractile activity in the dog. J Pharmacol Exp Ther 1970;172:367-76.

9. Bell JS, Go VL, DiMagno EP. The effect of smoking on the human interdigestive motor complex. Clin Res 1980;28:763. (Abst)

10. Painter NS. The cause of diverticular disease of the colon, its symptoms and its complications. Review and hypothesis. J R Coll Surg Edin 1985;30:118-22.

11. Sardi A, Gokli A, Singer JA. Diverticular disease of the cecum and ascending colon. A review of 881 cases. Am Surg 1987;53:41-5.

12. Cope GF, Heatley RV, Kelleher J, Lee PN. Cigarette smoking and inflammatory bowel disease: A review. Hum peripheral adrenergic nerves and the adrenal medulla, causing relaxation of the proximal colon (16)

In summary, in patients undergoing barium enema, no association was demonstrated between the presence of colonic diverticula and a history of cigarette smoking.

Toxicol 1987;6:189-93.

13. Zaridze DG, Peto R, eds. Tobacco, a Major International Health Hazard. Proceedings of an international meeting organized by the IARC and cosponsored by the All-Union Cancer Research Centre of the Academy of Medical Sciences of the USSR, Moscow, USSR, June 4-6, 1985. Lyon: International Agency for Research on Cancer, and New York: Oxford University Press, 1986 (IARC scientific publications no 74).

14. Almy TP, Howell DA. Diverticular disease of the colon. N Engl J Med 1980;302:324-31.

15. Bartlett L. Smoking: We cannot afford the cost. Can Med Assoc J 1988;138:644-5.

16. Carlson GM, Ruddon RW, Hug CC Jr, Schmiege SK, Bass P. Analysis of the site of nicotine action on gastric antral and duodenal contractile activity. J Pharmacol Exp Ther 1970;172:377-83. 


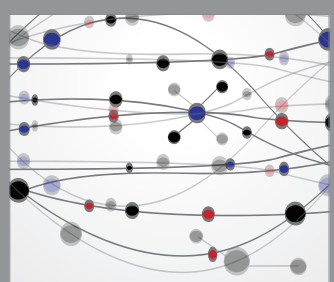

The Scientific World Journal
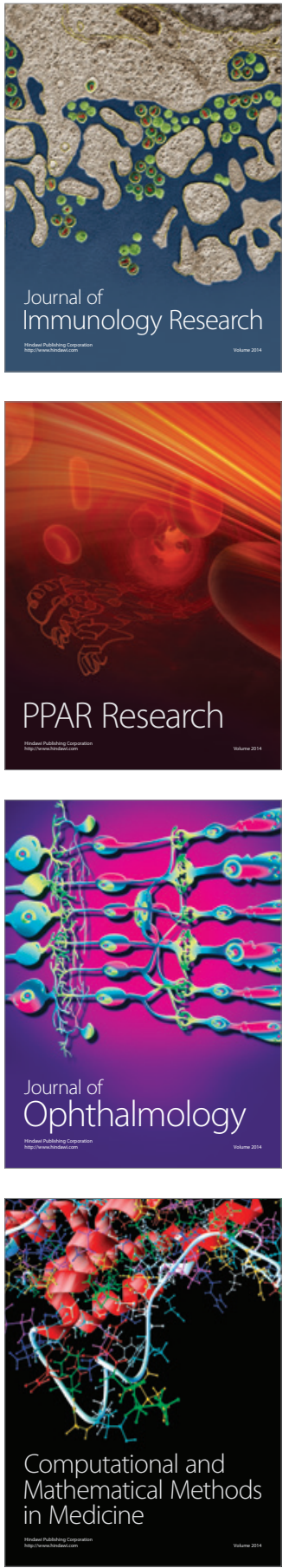

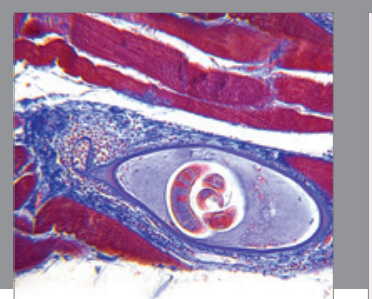

Gastroenterology Research and Practice

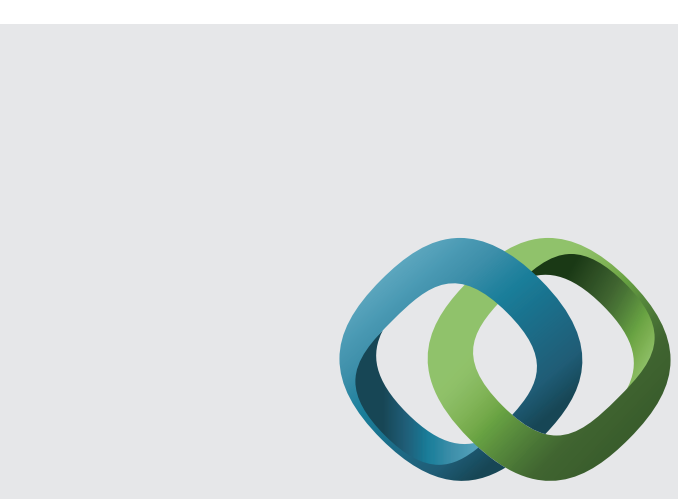

\section{Hindawi}

Submit your manuscripts at

http://www.hindawi.com
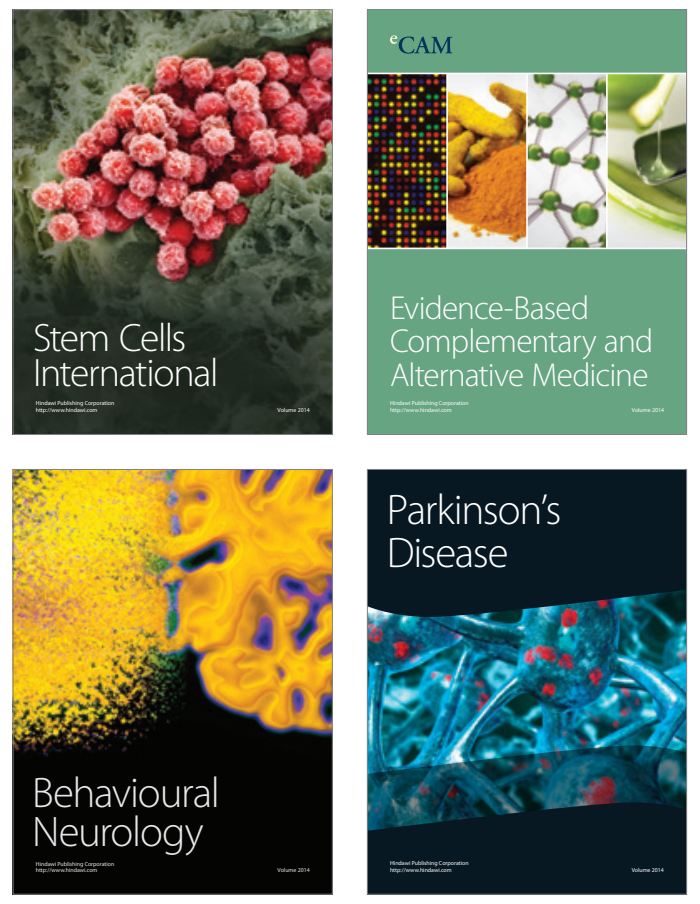
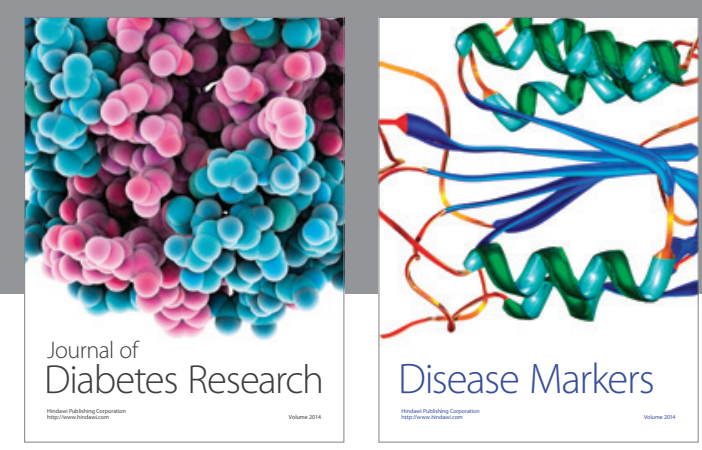

Disease Markers
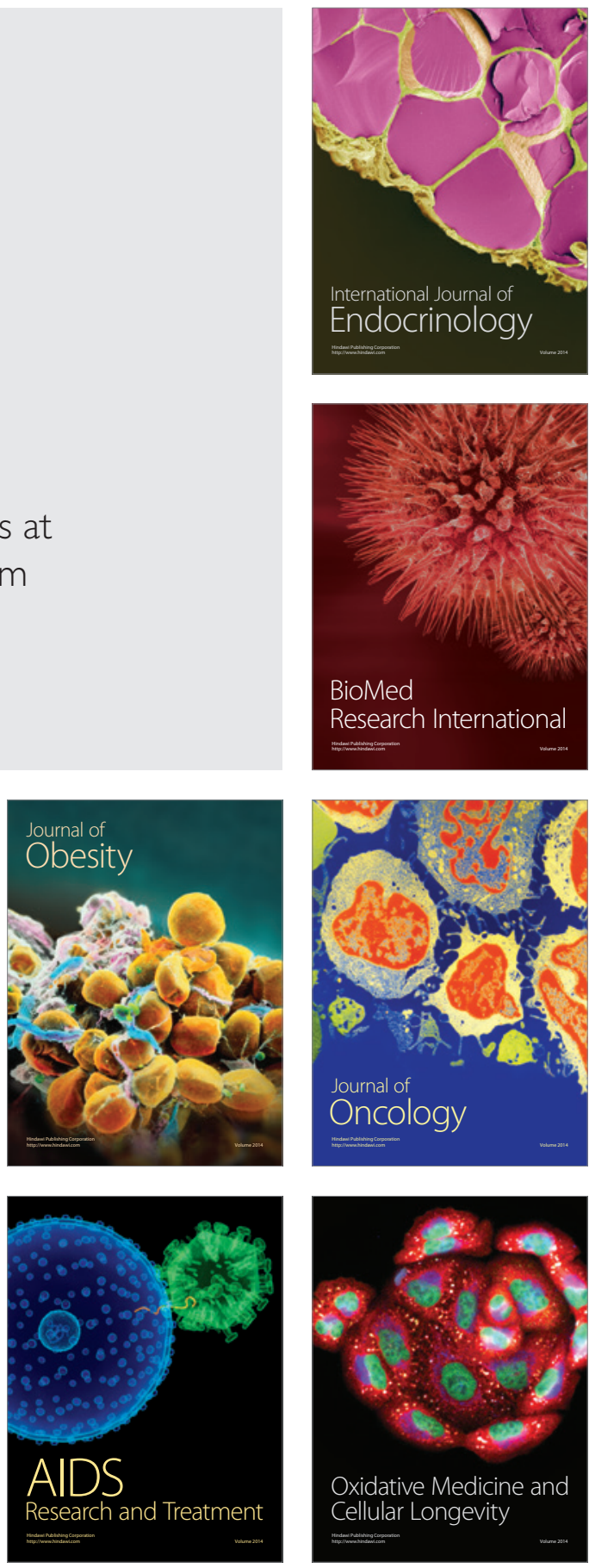